\title{
Una mujer con nódulos eritematovioláceos múltiples en la mama... (angiosarcoma en mama radiada)
}

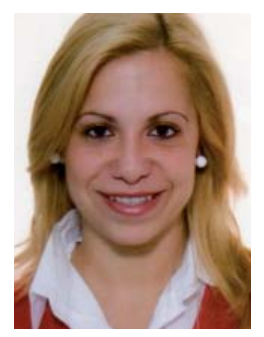

Marisol Contreras Steyls Médico adjunto. Servicio de Dermatología. Hospital La Línea. Línea de la Concepción. Cádiz
Mi paciente es una mujer de 70 años que fue remitida a la consulta de Dermatología para valoración de múltiples lesiones cutáneas asintomáticas situadas en la mama derecha de 6 meses de evolución. Como antecedentes personales de interés, cabe destacar que la paciente era obesa, padecía diabetes de tipo II, hipertensión arterial, dislipemia y además había sido diagnosticada de un carcinoma ductal infiltrante en la mama derecha en 2002 (T2 N0 M0, en estadio IIa según la clasificación UICC-TNM) tratado mediante cirugía conservadora, hormonoterapia con tamoxifeno $(20 \mathrm{mg}$ diarios durante 5 años) y radioterapia coadyuvante $\left({ }^{60} \mathrm{Co}\right.$ en mama, fosa supraclavicular y ápex axilar, 50 Gy y electrones de acelerador lineal de $12 \mathrm{Mev}$ en el lecho quirúrgico de la tumorectomía 16 Gy). En 2005, desarrolló un adenocarcinoma de endometrio que fue tratado mediante cirugía radical. A finales de 2009, comenzaron a aparecer las lesiones cutáneas por las que la paciente nos fue remitida.

La exploración física reveló la presencia en la mama derecha de numerosos nódulos tumorales eritematovioláceos que asentaban y confluían sobre una placa indurada de similares características clínicas. Estos nódulos presentaban una consistencia elástica, no estaban ulcerados y sus tamaños oscilaban entre $0,5 \mathrm{~cm} \mathrm{y}$
$2 \mathrm{~cm}$. El pezón no estaba afectado, aunque sí la areola mamaria (fig. 1).

A la palpación, no se detectaron adhesión al músculo pectoral ni adenopatías locorregionales. Tampoco se objetivaron signos de linfedema crónico en el miembro superior derecho. La paciente no presentaba ninguna sintomatología sistémica en el momento de la exploración.

Se realizaron exhaustivos estudios de laboratorio, en los que solo destacó un leve incremento de la LDH; el resto de los parámetros analíticos estaban dentro de la normalidad, incluidos los marcadores tumorales. La radiografía de tórax no mostró alteraciones significativas. Se realizó una tomografía axial computerizada del tronco, abdomen y zona pélvica, que no objetivó hallazgos patológicos. La

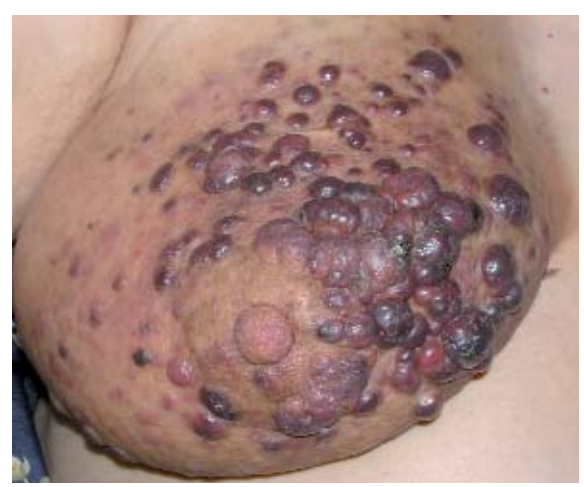

Figura 1. En la mama derecha, se observa la presencia de numerosos nódulos tumorales eritematovioláceos, que asientan sobre una placa indurada de similares características. 
mamografía reveló un engrosamiento cutáneo difuso inespecífico.

El estudio anatomopatológico con hematoxilinaeosina mostró una proliferación angiomatosa que ocupaba toda la dermis, llegaba hasta el tejido celular subcutáneo sin infiltrarlo y estaba formada por estructuras vasculares irregulares que disecaban los haces de colágeno, con paredes revestidas focalmente por varias capas de células endoteliales de aspecto epitelioide (fig. 2). Algunos vasos estaban entremezclados con áreas de hemorragia y mostraban células endoteliales con varios núcleos prominentes y de aspecto atípico. Se observó la presencia de algunas figuras mitóticas, pero no se vieron focos de necrosis. En la tinción inmunohistoquímica, las células tumorales fueron positivas para CD31 y CD34. El Ki67 mostró una positividad de más del 80\%.

Con estos datos epidemiológicos, clínicos e histopatológicos, se llegó al diagnóstico de angiosarcoma sobre mama radiada.

Se realizó una mastectomía total y posterior quimioterapia con paclitaxel $\left(80 \mathrm{mg} / \mathrm{m}^{2}\right.$ durante 50 ciclos) con buena tolerancia. A los 18 meses de su diagnóstico, la paciente no presenta signos de recidiva local o progresión sistémica.

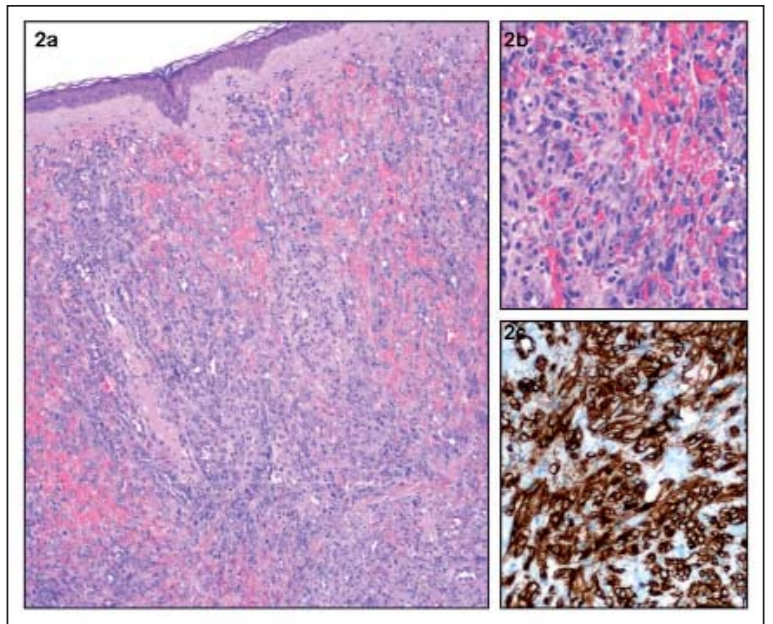

Figura 2. La tinción con hematoxilina-eosina muestra una proliferación angiomatosa que ocupa toda la dermis y llega al tejido celular subcutáneo sin infiltrarlo (2a); estaba formada por estructuras vasculares irregulares que disecaban los haces de colágeno, con paredes revestidas focalmente por varias capas de células endoteliales atípicas de aspecto epitelioide (2b). Las células tumorales mostraron positividad para CD31 y CD34 (2c).

\section{DISCUSIÓN}

Desde el inicio de la generalización del tratamiento conservador del carcinoma mamario consistente en combinar cirugía y radioterapia superficial, se ha descrito la aparición posterior de diferentes sarcomas radioinducidos, entre los que destaca por orden de frecuencia el angiosarcoma ${ }^{1}$. Estos tumores en mamas radiadas suelen ser superficiales, difícilmente afectan al parénquima subyacente y suelen desarrollarse en mujeres de más de 60 años después de unos 6-7 años de recibir la radioterapia. En cambio, los angiosarcomas primarios afectan al parénquima mamario y suelen diagnosticarse en mujeres de entre 20 y 40 años². Clínicamente, las lesiones son variadas y muestran cierta correlación con el grado de diferenciación histológica ${ }^{3}$. El tratamiento de estos angiosarcomas debe iniciarse con la realización de una resección quirúrgica agresiva, generalmente una mastectomía total. Las recidivas locales son frecuentes, a pesar de la resección amplia incluso con márgenes libres. Debido a la dificultad para controlar localmente el tumor únicamente con tratamiento quirúrgico, se ha planteado la radioterapia hiperfraccionada como terapia adyuvante ${ }^{4}$. En cuanto a la quimioterapia, solo el paclitaxel ha demostrado ser eficaz ${ }^{5}$.

El caso de nuestra paciente fue tratado mediante mastectomía total con posterior quimioterapia a base de paclitaxel y actualmente se encuentra libre de enfermedad. No obstante, en estas pacientes es necesario un seguimiento estrecho para detectar posibles recidivas y tratarlas precozmente.

\section{BIBLIOGRAFÍA}

1. Wang XY, Jakowski J, Tawfik OW, Thomas PA, Fan F. Angiosarcoma of the breast: a clinicopathologic analysis of cases from the last 10 years. Ann Diag Pathol. 2009;13:147-50.

2. Peramiquel L, Barnadas MA, Sancho J, Curell R, Alonso MC, Fuentes MJ, et al. Angiosarcoma en mama irradiada: descripción de un caso. Actas Dermosifiliogr. 2005;96(9):602-6.

3. Lucas DR. Angiosarcoma, radiation-associated angiosarcoma and atypical vascular lesion. Arch Pathol Lab Med. 2009;133:1804-9.

4. Abbott R, Palmieri C. Angiosarcoma of the breast following surgery and radiotherapy for breast cancer. Oncology. 2008;5(12):727-36.

5. Cozzio A. Complete remission in a patient with multifocal metastatic cutaneous angiosarcoma with a combination of paclitaxel and sorafenib. Br J Dermatol. 2010;162:695-701. 